\title{
Functional Consequences of Central Serotonin Depletion Produced by Repeated Fenfluramine Administration in Rats
}

\author{
Michael H. Baumann, Mario A. Ayestas, and Richard B. Rothman \\ Clinical Psychopharmacology Section, Intramural Research Program, National Institute on Drug Abuse, National Institutes \\ of Health, Baltimore, Maryland 21224
}

\begin{abstract}
Repeated administration of $\mathrm{D}, \mathrm{L}-$ fenfluramine (FEN) is known to cause prolonged depletion of forebrain serotonin (5-HT) in animals. Ironically, few studies have evaluated functional consequences of such FEN-induced 5-HT loss. In the present work, we examined neuroendocrine and behavioral responses evoked by acute FEN injection in rats that had previously received a $4 \mathrm{~d} F E N-d o s i n g$ regimen known to deplete forebrain 5-HT (D,L-FEN, $20 \mathrm{mg} / \mathrm{kg}$, s.C., b.i.d.). Rats were fitted with indwelling jugular catheters before the study to allow for repeated intravenous challenge injections and stress-free blood sampling. At 1 and 2 weeks after the $4 \mathrm{~d}$ dosing regimen, acute FEN (1.5 or $3.0 \mathrm{mg} / \mathrm{kg}$, i.v.) produced dose-related elevations in plasma corticosterone and prolactin; these hormonal responses were markedly attenuated in FEN-pretreated rats. Behavioral effects of acute FEN, namely flat body posture and forepaw treading, were also blunted in FEN-pretreated rats.
\end{abstract}

Interestingly, rats exposed to repeated FEN did not display overt abnormalities in hormonal or behavioral parameters under basal (i.e., unprovoked) conditions, despite dramatic decreases in postmortem tissue levels of 5-HT in numerous brain areas. Our results suggest that FEN-induced 5-HT depletion is accompanied by multiple impairments in 5-HT function. Although the clinical relevance of our data are debatable, the findings clearly show the utility of the FEN challenge test for uncovering in vivo functional deficits that might otherwise go undetected. FEN should remain an important pharmacological tool for determining the role of 5-HT neurons in mediating diverse physiological and behavioral processes.

Key words: fenfluramine; serotonin depletion; neuroendocrine; corticosterone; prolactin; behavior; neurotoxicity; serotonin function; rat
Fenfluramine ( $N$-ethyl- $\alpha$-methyl- $m$-[trifluoromethyl]-phenethylamine) is an appetite suppressant with proven efficacy (Silverstone, 1992). Two forms of the drug that exhibit similar pharmacology have been prescribed: the D,L-racemic mixture (FEN) and the more potent D-isomer (D-FEN) (McTavish and Heel, 1992). Despite structural similarities to amphetamine, FEN is not a locomotor stimulant and is seldom abused. The unique properties of FEN are related to its preferential activation of central serotonin (5-HT) neurons (for review, see Rowland and Carlton, 1986). For example, FEN stimulates 5-HT release and inhibits 5-HT reuptake in brain tissue preparations (Fuxe et al., 1975; Garattini et al., 1975). In vivo microdialysis studies in rat brain demonstrate that systemic or local administration of FEN elevates extracellular levels of 5-HT (Auerbach et al., 1989; Schwartz et al., 1989); this effect of FEN is blocked by 5-HT reuptake inhibitors like fluoxetine, suggesting involvement of 5-HT transporters (Berger et al., 1992; Sabol et al., 1992). Although FEN influences both 5-HT release and reuptake, the 5-HT-releasing capability of the drug appears to predominate in vivo (Fuller et al., 1988; Carboni et al., 1989).

A primary concern with the clinical use of FEN relates to its potential adverse effects on 5-HT neurons (for review, see Mc-

Received April 20, 1998; revised July 10, 1998; accepted Aug. 13, 1998.

This work was generously supported by the Intramural Research Program of the National Institute on Drug Abuse. We thank Turaya Bryant and Brian Reddick for their excellent technical assistance.

Correspondence should be addressed to Dr. Michael H. Baumann, Clinical Psychopharmacology Section, Intramural Research Program, National Institute on Drug Abuse, National Institutes of Health, P.O. Box 5180, 5500 Nathan Shock Drive, Baltimore, MD 21224. E-mail: mbaumann@intra.nida.nih.gov

Copyright (C) 1998 Society for Neuroscience 0270-6474/98/189069-09\$05.00/0
Cann et al., 1997). It is well known that administration of FEN at sufficient doses can cause long-lasting ( $>2$ weeks) depletion of 5-HT in rodent brain (Clineschmidt et al., 1976; Harvey and McMaster, 1975; Sanders-Bush et al., 1975). Such depletions are associated with a loss of 5-HT-immunoreactive nerve fibers (Appel et al., 1989; Molliver and Molliver, 1990) and a reduction in 5-HT reuptake sites (Appel et al., 1990; Zaczek et al., 1990). The deleterious effects of FEN on 5-HT systems have been reported in every animal species examined to date (McCann et al., 1997), prompting speculation that FEN is a 5-HT neurotoxin that may be hazardous to human patients (Ricaurte et al., 1991; McCann et al., 1994).

Interestingly, few preclinical studies have found impairments in 5-HT function after FEN-induced 5-HT depletion (for review, see Ricaurte et al., 1994). This observation could be regarded as evidence for a lack of such deficits; alternatively, more sensitive testing methods may be required to reveal subtle changes in 5-HT neuronal dynamics. In the present study, we used an in vivo pharmacological approach to assess the functional integrity of 5-HT neurons in FEN-treated rats. More specifically, we evaluated neuroendocrine and behavioral responses elicited by acute FEN challenge in rats that had previously received a $4 \mathrm{~d}$ FENdosing regimen known to deplete central 5-HT $(20 \mathrm{mg} / \mathrm{kg}$, s.c., b.i.d., 4 d). The stimulatory effect of acute FEN on circulating adrenocorticotropin (ACTH), corticosteroids, and prolactin is well documented in both animals and humans (Van de Kar, 1991; Yatham and Steiner, 1993). Because these FEN-evoked hormonal changes are mediated, at least in part, by activation of 5-HT pathways in the hypothalamus (Levy et al., 1994a), they can be used as sensitive measures of brain 5-HT function. It is 
noteworthy that FEN challenge tests have been widely used by clinical investigators to demonstrate changes in 5-HT sensitivity associated with depression and other psychiatric disorders (Siever et al., 1991).

\section{MATERIALS AND METHODS}

Animals and surgery. Male Sprague Dawley rats weighing 250-300 gm were housed in standard vivarium conditions (lights on, 7:00 A.M.-7:00 P.M.) with ad libitum access to food and water. Animals were maintained in facilities fully accredited by the American Association of the Accreditation of Laboratory Animal Care, and experiments were performed in accordance with the Animal Care and Use Committee of the National Institute on Drug Abuse (NIDA) Intramural Research Program (IRP). All of the rats in our studies were anesthetized with methoxyflurane (Pittman-Moore, Phillipsburg, NJ), and indwelling jugular catheters were surgically implanted as described (Baumann et al., 1995). Briefly, catheters $(0.5 \mathrm{~mm}$ inner diameter, $1.0 \mathrm{~mm}$ outer diameter $)$ were made by joining $8 \mathrm{~cm}$ of vinyl tubing to $3 \mathrm{~cm}$ of SILASTIC (Dow Corning, Midland, MI) tubing with a $1 \mathrm{~cm} 23$ gauge needle tube connector. During surgery, the SILASTIC end of the catheter was inserted into the jugular vein and advanced to the atrium, whereas the vinyl end was exteriorized on the nape of the neck. Rats were singly housed postoperatively and allowed 1 week to recover; during this period catheters were flushed daily with $0.3 \mathrm{ml}$ of $50 \mathrm{IU} / \mathrm{ml}$ heparin saline.

Intravenous challenge test procedures. On the day of a challenge test, rats were moved to the laboratory in their home cages at 10:00-11:00 A.M. One hour later, polyethylene extension tubes (PE 50, Clay Adams, Parsippany, NJ) were connected to intravenous catheters and threaded outside of the cages. This arrangement enabled the investigator to perform intravenous injections and serial blood sampling without disturbing the rats. Furthermore, the rats were able to move freely about the cage during the experimental sessions. Catheters were flushed with 0.3 $\mathrm{ml}$ of $50 \mathrm{IU} / \mathrm{ml}$ heparin saline, and acute intravenous challenge injections were administered between 12:00 and 3:00 P.M. In all cases, blood samples $(0.5 \mathrm{ml})$ were withdrawn via the catheters immediately before and at 15, 30, and $60 \mathrm{~min}$ after intravenous injections. Blood was collected into $1 \mathrm{ml}$ syringes, transferred to $1.5 \mathrm{ml}$ tubes, and spun for 10 $\mathrm{min}$ at $5000 \mathrm{rpm}$. Plasma was decanted and stored at $-80^{\circ} \mathrm{C}$ until the time of assay.

Acute fluoxetine pretreatment study. Because there is disagreement in the literature concerning the role of 5-HT neurons in mediating FENinduced corticosterone secretion (McElroy et al., 1984; Van de Kar et al., 1985), we first assessed the ability of fluoxetine pretreatment to affect FEN-induced neuroendocrine secretion. Groups of rats were pretreated with intraperitoneal fluoxetine $(5 \mathrm{mg} / \mathrm{kg})$ or its water vehicle $(1 \mathrm{ml} / \mathrm{kg})$, $2 \mathrm{hr}$ before receiving intravenous challenge injection of FEN (D,Lracemic mixture given at $3 \mathrm{mg} / \mathrm{kg})$ or its saline vehicle $(1 \mathrm{ml} / \mathrm{kg})$. Fluoxetine $\mathrm{HCl}$ was generously provided by Eli Lilly and Company (Indianapolis, IN), whereas FEN was obtained from the NIDA IRP Pharmacy (Baltimore, MD). Drugs were dissolved in their respective vehicles immediately before use. Serial blood samples were withdrawn, and plasma was collected as described above.

Repeated FEN administration study. Rats were randomly assigned to groups receiving a $4 \mathrm{~d}$ injection regimen of either FEN (D,L-racemic mixture given at $20 \mathrm{mg} / \mathrm{kg}$, s.c., b.i.d.) or saline $(1 \mathrm{ml} / \mathrm{kg}$, s.c., b.i.d.). Similar repeated FEN-dosing procedures have been shown to cause long-lasting depletion of forebrain 5-HT in rats (Appel et al., 1989; Zaczek et al., 1990). One week after the final injection of the $4 \mathrm{~d}$ regimen, rats received acute intravenous challenge injections of FEN $(1.5$ or $3.0 \mathrm{mg} / \mathrm{kg})$ or saline $(1 \mathrm{ml} / \mathrm{kg})$. Serial blood samples were withdrawn, and plasma was collected as described above. The intravenous doses of FEN used herein have been shown to produce significant increases in circulating corticosterone in rats (Baumann et al., 1995). The challenge test procedure was repeated 1 week later (i.e., 2 weeks after cessation of repeated treatment) so that all rats were tested twice with the identical acute treatment.

The occurrence of specific 5-HT-mediated behaviors was evaluated in the same subjects during the test sessions. At 2, 10, 20, and 30 min after intravenous injections, rats were observed, and the presence of forepaw treading (FPT), flat body posture (FBP), and penile erections (PE) were scored using the graded scale: $0=$ absent, $1=$ equivocal, $2=$ present, and 3 = intense (Tricklebank et al., 1985). Rats were given a single score for each behavior that consisted of the summed scores across all time points.
Table 1. Microdissection of discrete brain areas

\begin{tabular}{|c|c|c|c|c|}
\hline Brain region & $\begin{array}{l}\text { Anterior } \\
\text { coordinate }^{a} \\
(\mu \mathrm{m})\end{array}$ & $\begin{array}{l}\text { Sections/ } \\
\text { brain }\end{array}$ & $\begin{array}{l}\text { Punches/ } \\
\text { brain }\end{array}$ & $\begin{array}{l}\text { Cannula } \\
\text { diameter } \\
(\mu \mathrm{m})\end{array}$ \\
\hline Caudate putamen (CP) & A1800-1500 & 2 & 4 & 1000 \\
\hline Nucleus accumbens (NAC) & A2100-1800 & 3 & 6 & 800 \\
\hline Olfactory tubercle (OT) & A1800-1500 & 2 & & $\mathrm{Knife}^{b}$ \\
\hline Hippocampus CA3 (HIP) & P2400-3000 & 3 & 6 & 800 \\
\hline $\begin{array}{l}\text { Lateral hypothalamus } \\
\qquad(\mathrm{LH})\end{array}$ & P2400-3000 & 3 & 6 & 800 \\
\hline $\begin{array}{l}\text { Ventromedial hypothala- } \\
\text { mus (VMH) }\end{array}$ & P2400-3000 & 3 & 6 & 600 \\
\hline $\begin{array}{l}\text { Basolateral amygdala } \\
\text { (AMY) }\end{array}$ & P2400-3000 & 3 & 6 & 600 \\
\hline
\end{tabular}

$\overline{{ }^{a} \text { Anterior coordinates refer to the rostral face of the sections relative to bregma, }}$ according to the maps of Palkovits and Brownstein (1988).

${ }^{b}$ Olfactory tubercle was excised from the sections using a microdissecting knife.

Prolactin and corticosterone radioimmunoassays. Plasma hormone levels were quantified using double-antibody radioimmunoassay (RIA) procedures. Samples from the fluoxetine experiments and the repeated FENdosing experiments were analyzed in separate assays. Corticosterone levels were determined using commercially available $\left[{ }^{125} \mathrm{I}\right]-$ corticosterone RIA kits (ICN Biomedicals, Irvine, CA). Plasma samples $(10 \mu \mathrm{l})$ were aliquoted in duplicate, and the average intra-assay coefficient of variability was $6.5 \%$. Prolactin levels were determined using materials generously provided by the National Hormone and Pituitary Program (Rockville, MD). Antiserum directed against rat prolactin (rPRL-S-9) was diluted 1:437,500, and rPRL-RP-3 was the reference standard. [ $\left.{ }^{125} \mathrm{I}\right]$-Prolactin was obtained from Hazleton Laboratories (Vienna, VA). Plasma samples $(50 \mu \mathrm{l})$ were aliquoted in duplicate, and the intra-assay coefficient of variability was $7.8 \%$.

Microdissection and neurotransmitter analyses. Rats from the repeated FEN-dosing study that received acute saline challenge (i.e., repeated saline/acute saline and repeated FEN/acute saline) were killed by decapitation shortly after the 2 week test. Brains were rapidly removed, frozen on dry ice, and stored at $-80^{\circ} \mathrm{C}$. The postmortem tissue levels of 5-HT and its metabolite, 5-hydroxyindoleacetic acid (5-HIAA), were determined in various brain regions to verify the extent of 5-HT depletion produced by the $4 \mathrm{~d}$ FEN-dosing regimen. Coronal sections $300 \mu \mathrm{m}$ in thickness were cut from frozen brains, and discrete regions were microdissected using stainless steel needle tubing as described (Palkovits and Brownstein, 1988). Specific brain regions and their respective locations relative to bregma are summarized in Table 1.

Tissue punches of a given region from individual rats were homogenized in $100 \mu \mathrm{l}$ of cold $0.1 \mathrm{~N}$ perchloric acid and centrifuged at 15,000 $\mathrm{rpm}$ for $15 \mathrm{~min}$. The concentrations of 5-HT and 5-HIAA were quantified in the supernatant using high-pressure liquid chromatography coupled to electrochemical detection (HPLC-EC) according to published methods (Baumann et al., 1993). Briefly, $20 \mu$ l aliquots of supernatant were injected onto a $\mathrm{C}-18$ reversed-phase column that was linked to a coulometric electrochemical detection system (Environmental Sciences Associates, Bedford, MA). Mobile phase consisting of $50 \mathrm{~mm}$ sodium phosphate monobasic (pH 2.75), $250 \mu \mathrm{M} \mathrm{Na} \mathrm{Na}_{2}$ EDTA, $0.025 \%$ sodium octane sulfonic acid, and $25 \%$ methanol was recirculated at a flow rate of $0.7 \mathrm{ml} / \mathrm{min}$. Chromatographic data were exported to a MAXIMA 820 software system (Waters Associates, Milford, MA) for peak amplification, integration, and analysis. Peak heights of unknowns were compared with peak heights of 5-HT and 5-HIAA standards. The lower limit of detectability $(3 \times$ baseline noise level) was $10 \mathrm{pg}$ for both analytes. Tissue pellets were resolubilized in $1.0 \mathrm{~N} \mathrm{NaOH}$ and assayed for protein (Bradford, 1976).

Data analysis. All data are expressed as mean \pm SEM for $n=7$ or 8 rats per group. Hormone data were evaluated using a two-way (pretreatment $\times$ acute treatment) ANOVA with repeated measures, whereas behavioral data were evaluated using two-way ANOVA (pretreatment $\times$ acute treatment). Neurochemical data were evaluated using one-way (pretreatment) ANOVA. When significant $F$ values were obtained, Duncan's Multiple Range test was performed to determine differences ( $p<$ $0.05)$ between group means. 


\begin{tabular}{|c|c|c|c|c|c|}
\hline Pretreatment & Treatment & $t=0 \min$ & $+15 \min$ & $+30 \mathrm{~min}$ & $+60 \min$ \\
\hline Water & Saline & $105.3 \pm 25.8$ & $104.9 \pm 10.0$ & $117.4 \pm 21.7$ & $53.9 \pm 11.4$ \\
\hline Water & Fenfluramine & $80.7 \pm 16.2$ & $279.5 \pm 13.8$ & $349.9 \pm 24.9$ & $287.1 \pm 28.6$ \\
\hline Fluoxetine & Saline & $87.4 \pm 15.5$ & $103.2 \pm 17.4$ & $108.7 \pm 20.8$ & $94.7 \pm 30.3$ \\
\hline Fluoxetine & Fenfluramine & $93.0 \pm 23.5$ & $199.2 \pm 19.2^{*}$ & $200.2 \pm 19.2^{*}$ & $177.0 \pm 14.8^{*}$ \\
\hline
\end{tabular}

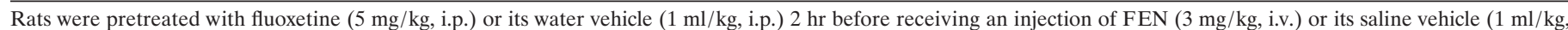

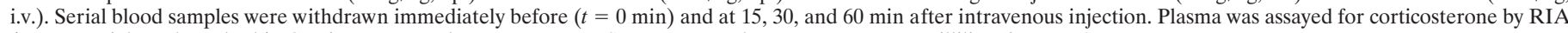
(see Materials and Methods). Corticosterone values are mean \pm SEM expressed as nanograms per milliliter for $n=8$ rats per group.

${ }^{*} p<0.05$ compared to corresponding water-pretreated group at a specific time point.

\section{Table 3. Effects of fluoxetine pretreatment on fenfluramine-induced prolactin secretion}

\begin{tabular}{|c|c|c|c|c|c|}
\hline Pretreatment & Treatment & $t=0 \mathrm{~min}$ & $+15 \min$ & $+30 \mathrm{~min}$ & $+60 \mathrm{~min}$ \\
\hline Water & Saline & $4.9 \pm 1.1$ & $2.7 \pm 0.3$ & $2.5 \pm 0.2$ & $3.9 \pm 0.5$ \\
\hline Water & Fenfluramine & $4.8 \pm 0.6$ & $37.5 \pm 4.6$ & $28.7 \pm 4.2$ & $13.9 \pm 1.5$ \\
\hline Fluoxetine & Saline & $6.4 \pm 0.6$ & $4.6 \pm 0.6$ & $3.3 \pm 0.5$ & $3.4 \pm 0.5$ \\
\hline Fluoxetine & Fenfluramine & $4.3 \pm 1.0$ & $17.9 \pm 2.7^{*}$ & $11.8 \pm 1.4^{*}$ & $5.1 \pm 0.8^{*}$ \\
\hline
\end{tabular}

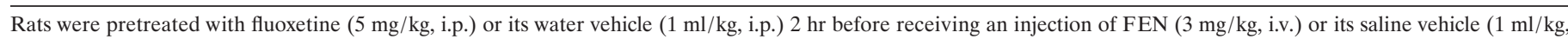

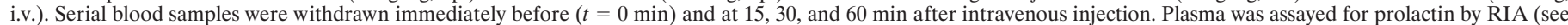

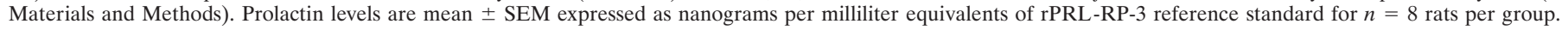

${ }^{*} p<0.05$ compared to corresponding water-pretreated group at a specific time point.

\section{Pretreatment: $\quad-0-$ Saline $\rightarrow-$ Fenfluramine}

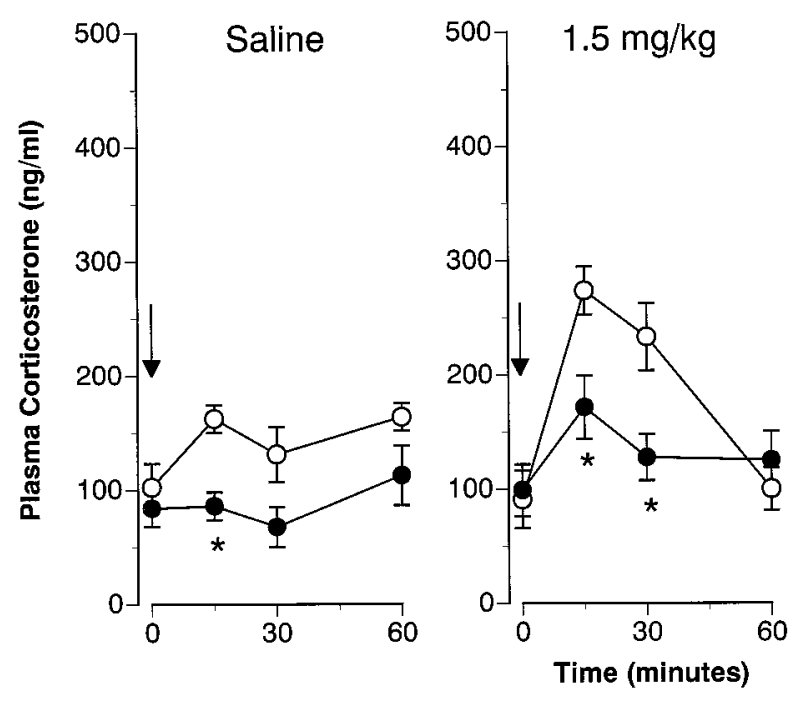

\section{RESULTS}

\section{Fluoxetine pretreatment study}

Tables 2 and 3 summarize the effect of fluoxetine pretreatment on FEN-induced secretion of corticosterone and prolactin. Fluoxetine did not influence baseline (time $0 ; t=0 \mathrm{~min}$ ) levels of either hormone. As shown in Table 2, FEN produced a sustained rise in plasma corticosterone $\left(F_{(1,28)}=55.49 ; p<0.0001\right)$, and this response was diminished in rats pretreated with fluoxetine (pretreatment $\times$ acute treatment interaction: $F_{(1,28)}=10.52 ; p<$ $0.003)$. Similarly, Table 3 shows that FEN elevated plasma prolactin $\left(F_{(1,28)}=60.54 ; p<0.0001\right)$, and this response was reduced by fluoxetine pretreatment (pretreatment $\times$ acute treatment interaction: $\left.F_{(1,28)}=15.55 ; p<0.001\right)$. Post hoc tests revealed that fluoxetine significantly attenuated FEN-induced corticosterone and prolactin secretion at all time points after intravenous chal-

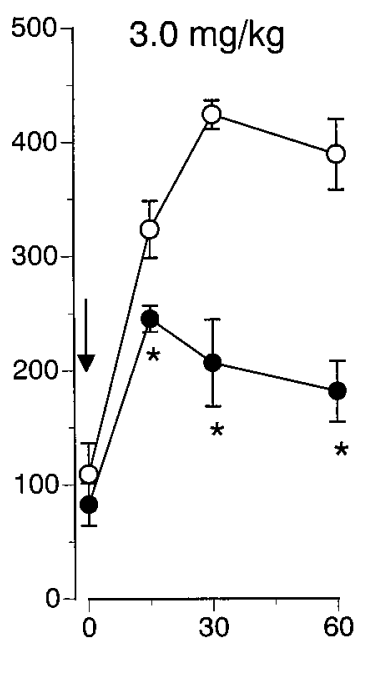

Figure 1. FEN-induced corticosterone release determined 1 week after cessation of the $4 \mathrm{~d}$ saline (1 $\mathrm{ml} / \mathrm{kg}$, s.c., b.i.d.) or FEN (20 mg/kg, s.c., b.i.d.) dosing regimen. Rats from each pretreatment group were challenged with intravenous saline or FEN $(1.5$ or $3.0 \mathrm{mg} / \mathrm{kg})$. Serial blood samples were withdrawn immediately before (time 0 ) and at 15,30 , and $60 \mathrm{~min}$ after intravenous injection. Corticosterone values are mean \pm SEM for $n=8$ rats per group. ${ }^{*} p<0.05$ with respect to corresponding saline pretreatment group at the specified time point. lenge injection. It is noteworthy, however, that fluoxetine pretreatment did not completely block the hormonal effects elicited by FEN.

\section{Repeated FEN-dosing study: neuroendocrine findings}

Figures 1 and 2 illustrate the corticosterone responses evoked by intravenous FEN challenge administered 1 and 2 weeks after cessation of the $4 \mathrm{~d}$ saline or FEN treatment regimen. Baseline (time 0 ) hormone levels were not altered by the repeated FENdosing regimen on either challenge day. As depicted in Figure 1, acute FEN increased corticosterone in a dose-related manner at 1 week $\left(F_{(2,42)}=37.99 ; p<0.00001\right)$. There was a significant main effect of pretreatment $\left(F_{(1,42)}=39.8 ; p<0.00001\right)$ and a significant pretreatment $\times$ acute treatment interaction $\left(F_{(2,42)}=\right.$ 5.6; $p<0.01)$. Post hoc tests demonstrated that corticosterone 
Pretreatment: $\quad-\circ$ Saline $\quad \rightarrow$ Fenfluramine

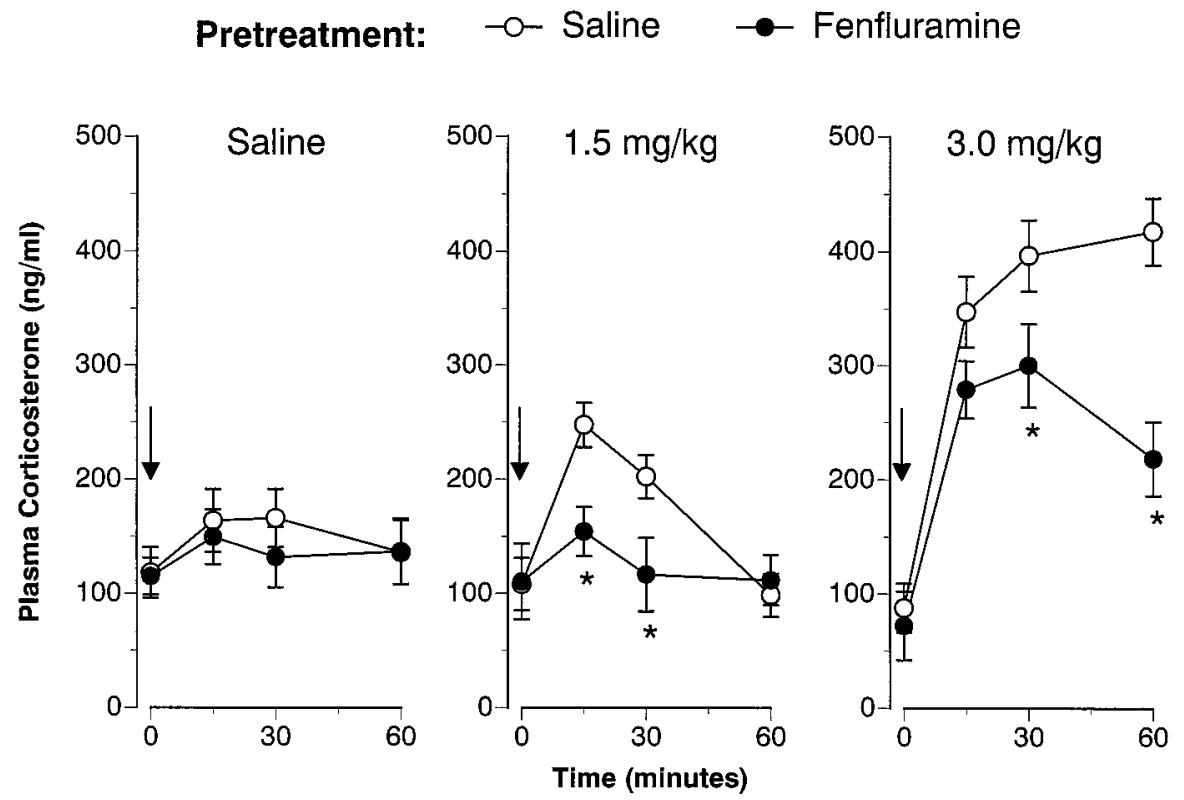

Pretreatment:
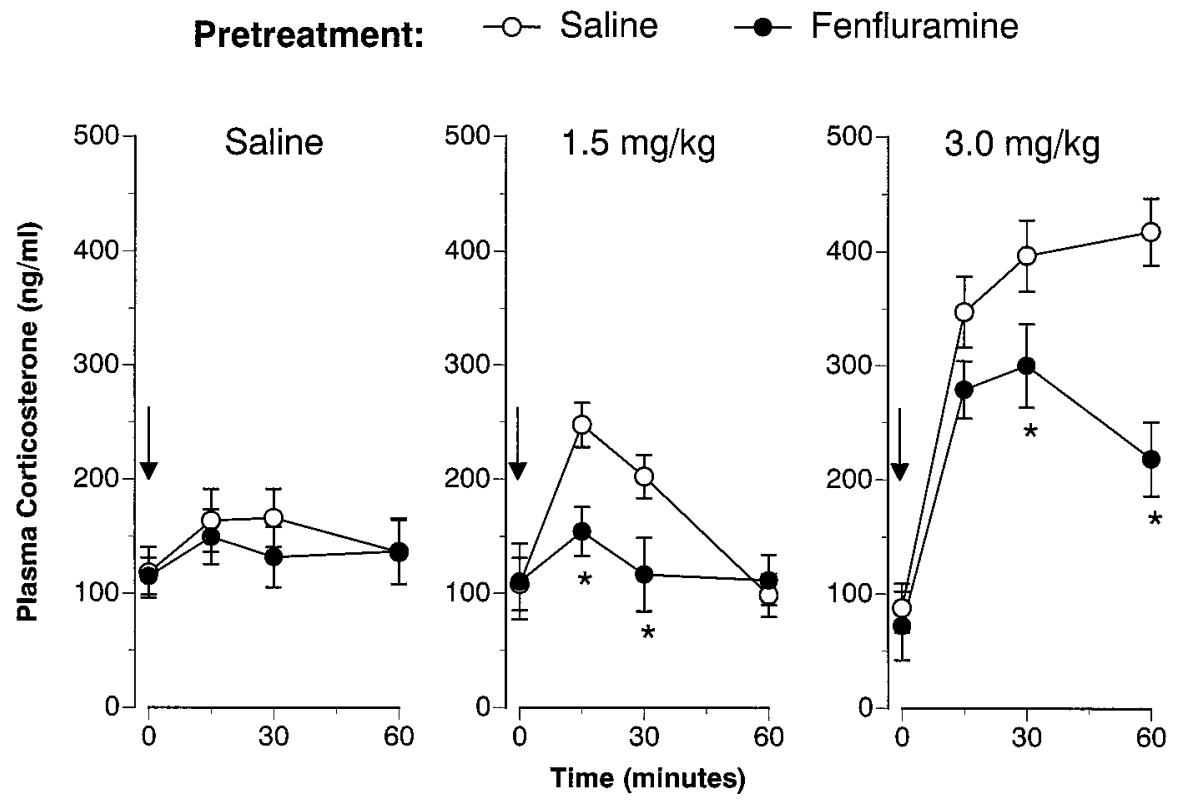

per group. $* p<0.05$ with respect to corresponding saline pretreatment group.

$-\circ$ Saline $\quad \bullet$ Fenfluramine
Figure 3. FEN-induced prolactin secretion determined 1 week after cessation of the $4 \mathrm{~d}$ saline $(1$ $\mathrm{ml} / \mathrm{kg}$, s.c., b.i.d.) or FEN ( $20 \mathrm{mg} / \mathrm{kg}$, s.c., b.i.d.) dosing regimen. Rats from each pretreatment group were challenged with intravenous saline or FEN (1.5 or $3.0 \mathrm{mg} / \mathrm{kg}$ ). Serial blood samples were withdrawn immediately before (time 0 ) and at 15,30 , and $60 \mathrm{~min}$ after intravenous injection. Prolactin levels are mean \pm SEM expressed as nanogram per milliliter equivalents of rPRL-RP-3 for $n=8$ rats per group. ${ }^{*} p<0.05$ with respect to corresponding saline pretreatment group at the specified time point.
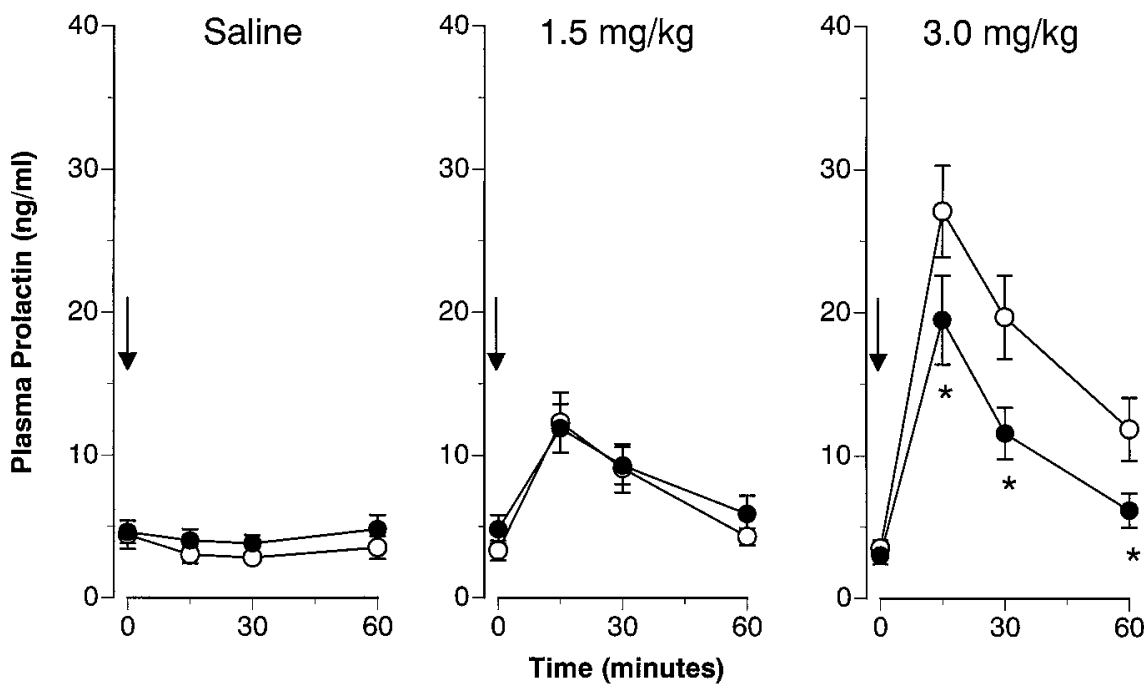

responses in FEN-pretreated rats were significantly diminished after all intravenous challenge conditions, i.e., saline (zero dose), $1.5 \mathrm{mg} / \mathrm{kg} \mathrm{FEN}$, and $3.0 \mathrm{mg} / \mathrm{kg}$ FEN. Analogous to the 1 week findings, Figure 2 shows that acute FEN increased corticosterone at 2 weeks $\left(F_{(2,42)}=31.7 ; p<0.00001\right)$, and this effect was modified by pretreatment condition $\left(F_{(1,42)}=9.75 ; p<0.01\right)$. Post $h o c$ tests revealed that corticosterone responses were blunted in FEN-pretreated rats at 1.5 and $3.0 \mathrm{mg} / \mathrm{kg}$ doses of acute FEN.

Figures 3 and 4 illustrate the FEN-induced prolactin responses 1 and 2 weeks after the $4 \mathrm{~d}$ saline or FEN treatment regimen. Baseline (time 0) prolactin levels were not affected by the repeated FEN-dosing regimen on either challenge day. As depicted in Figure 3, acute FEN elevated plasma prolactin in a doserelated manner at 1 week $\left(F_{(2,42)}=27.85 ; p<0.00001\right)$. Although there was no main effect of pretreatment $\left(F_{(1,42)}=3.16 ; p<\right.$ $0.08)$, a significant pretreatment $\times$ acute treatment interaction was noted $\left(F_{(2,42)}=4.47 ; p<0.02\right)$. Post hoc evaluation demon- strated that FEN-pretreated rats had attenuated prolactin responses after the high $(3.0 \mathrm{mg} / \mathrm{kg})$ challenge dose of FEN. The data presented in Figure 4 show that acute FEN elevated plasma prolactin at 2 weeks $\left(F_{(2,42)}=36.18 ; p<0.0001\right)$. There was a main effect of pretreatment $\left(F_{(1,42)}=9.27 ; p<0.01\right)$ and a significant acute $\times$ pretreatment interaction $\left(F_{(2,42)}=11.61 ; p<\right.$ 0.0001). Post hoc tests revealed that the FEN-induced prolactin response was again blunted only at the $3.0 \mathrm{mg} / \mathrm{kg}$ challenge dose of FEN.

\section{Repeated FEN-dosing study: behavioral findings}

Table 4 shows the effects of the $4 \mathrm{~d}$ FEN-dosing regimen on body weight for all rats used in this study. FEN exposure significantly reduced the body weight gain of rats when assessed at 1 week $\left(F_{(1,42)}=49.91 ; p<0.0001\right)$ and 2 weeks $\left(F_{(1,42)}=15.61 ; p<\right.$ $0.0004)$ after the last repeated dose. Figures 5 and 6 depict the effect of acute FEN challenge on 5-HT-mediated behaviors 1 and 


\section{Pretreatment: $\quad-\circ$ - Saline $\quad \rightarrow$ Fenfluramine}
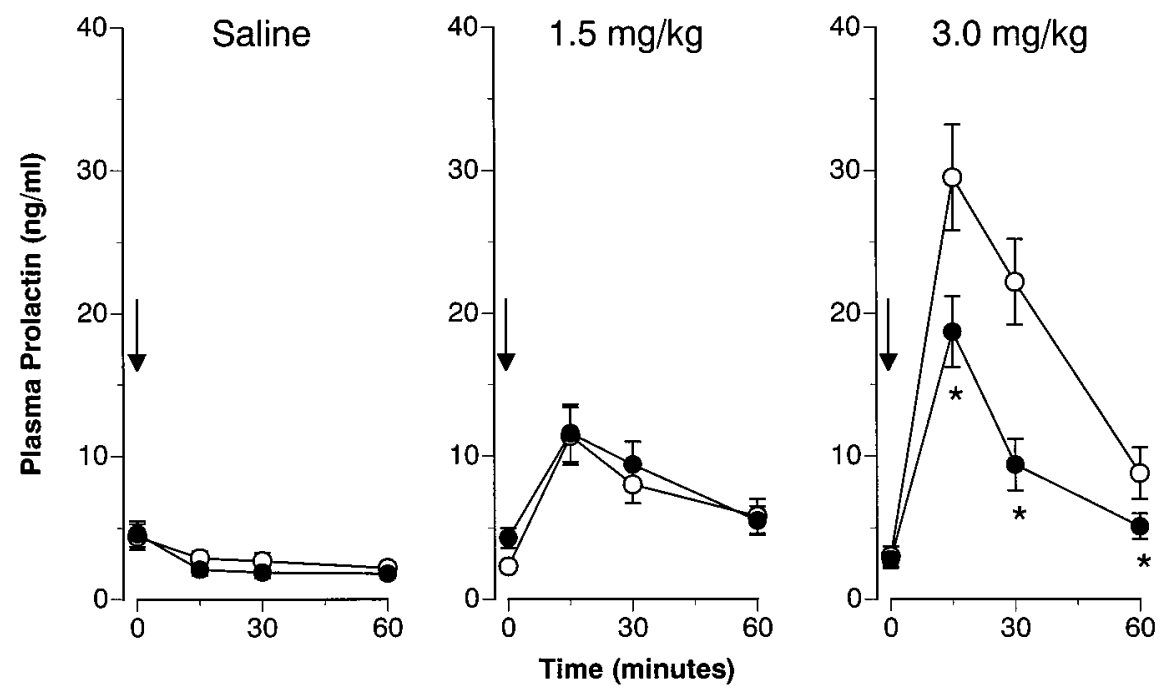

Figure 4. FEN-induced prolactin secretion assessed 2 weeks after the $4 \mathrm{~d}$ saline or FEN-dosing regimen. The data depicted here are obtained from the same subjects described in Figure 3. Refer to the legend of Figure 3 for further details. $n=7$ or 8 rats per group. ${ }^{*} p<0.05$ with respect to corresponding saline pretreatment group.
Table 4. Effects of the $4 \mathrm{~d}$ fenfluramine dosing regimen on body weight

\begin{tabular}{lll} 
Experimental day & $\begin{array}{l}4 \mathrm{~d} \text { saline } \\
(1 \mathrm{ml} / \mathrm{kg}, \\
\text { s.c., bid })\end{array}$ & $\begin{array}{l}4 \mathrm{~d} \text { fenfluramine } \\
(20 \mathrm{mg} / \mathrm{kg} \text { FEN, } \\
\text { s.c., bid })\end{array}$ \\
\hline Day 1 of $4 \mathrm{~d}$ dosing & $344.3 \pm 3.8$ & $337.0 \pm 4.6$ \\
1 week after last dose & $386.8 \pm 7.7$ & $345.8 \pm 6.3^{*}$ \\
2 weeks after last dose & $412.2 \pm 11.4$ & $385.0 \pm 7.4^{*}$ \\
\hline
\end{tabular}

Rats received saline $(1 \mathrm{ml} / \mathrm{kg}$, s.c., bid) or FEN $(20 \mathrm{mg} / \mathrm{kg}$, s.c., bid) treatments for 4 consecutive days. Rats were weighed on day 1 of the $4 \mathrm{~d}$ dosing regimen, and at 1 and 2 weeks after the final treatment (i.e. on challenge test day). Body weights in grams are mean \pm SEM for $n=24$ rats per group.

${ }^{*} p<0.05$ with respect to corresponding saline control group.

2 weeks after the $4 \mathrm{~d}$ saline or FEN pretreatment. As shown in Figure 5, acute FEN increased flat body posture at 1 week $\left(F_{(2,42)}=5.77 ; p<0.006\right)$. There was a main effect of pretreatment $\left(F_{(1,42)}=18.47 ; p<0.0001\right)$ and a significant pretreatment $\times$ acute treatment interaction $\left(F_{(2,42)}=6.44 ; p<0.004\right)$. Post hoc tests revealed the occurrence of FEN-induced flat body posture was virtually absent in FEN-pretreated rats. Acute FEN also increased the incidence of forepaw treading $\left(F_{(1,42)}=16.60\right.$; $p<0.0001)$, and this behavioral effect was influenced by previous FEN exposure $\left(F_{(1,42)}=4.76 ; p<0.04\right)$. In this case, post hoc tests showed that forepaw treading was attenuated in FENpretreated rats only at the highest challenge dose of FEN (3.0 $\mathrm{mg} / \mathrm{kg}$ ). FEN challenge stimulated penile erections at 1 week $\left(F_{(2,42)}=9.93 ; p<0.0003\right)$, but this effect was not modified by the $4 \mathrm{~d}$ FEN-dosing regimen $\left(F_{(1,42)}=0.38 ; p<0.54\right)$. The data illustrated in Figure 6 show that the behavioral results from the 2 week FEN challenge tests were very similar to those from the 1 week challenge sessions.

\section{Repeated FEN-dosing study: neurochemical findings}

Figures 7 and 8 summarize the postmortem tissue levels of 5-HT and 5-HIAA from the brains of acute saline-treated rats killed 2 weeks after the $4 \mathrm{~d}$ FEN regimen. Figure 7 shows that repeated FEN significantly reduced 5-HT in forebrain areas such as the caudate putamen $\left(45 \%\right.$ decrease) $\left(F_{(1,14)}=16.32 ; p<0.001\right)$, olfactory tubercle $(50 \%$ decrease $)\left(F_{(1,14)}=15.19 ; p<0.01\right)$,

\section{Pretreatment: $\square$ Saline $\quad$ Fenfluramine}
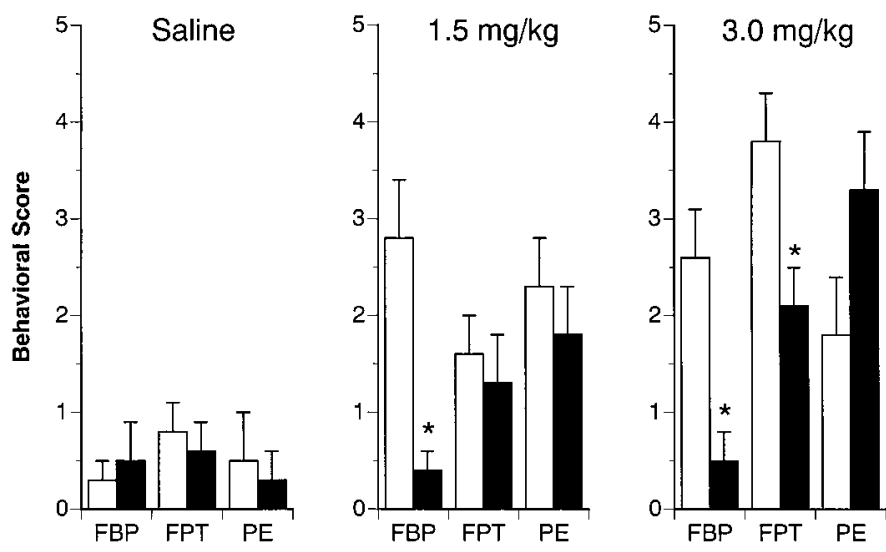

Figure 5. FEN-induced behavioral responses determined 1 week after cessation of the $4 \mathrm{~d}$ saline $(1 \mathrm{ml} / \mathrm{kg}$, s.c., b.i.d.) or FEN $(20 \mathrm{mg} / \mathrm{kg}$, s.c., b.i.d.) dosing regimen. Rats from each pretreatment group were challenged with intravenous saline or FEN $(1.5$ or $3.0 \mathrm{mg} / \mathrm{kg})$. The occurrence of flat body posture $(F B P)$, forepaw treading $(F P T)$, and penile erections $(P E)$ was assessed at $2,10,20$, and $30 \mathrm{~min}$ after injection. Numerical scores were recorded for each behavior at each time point according to a graded rating scale (see Materials and Methods). Rats received a final "behavioral score" for each behavior, which consisted of the summed scores for that behavior over all time points. Data are expressed as mean \pm SEM for $n=8$ rats per group. ${ }^{*} p<0.05$ with respect to corresponding saline pretreatment group.

hippocampus (55\% decrease) $\left(F_{(1,14)}=19.14 ; p<0.001\right)$, and amygdala $(45 \%$ decrease $)\left(F_{(1,14)}=17.38 ; p<0.001\right)$. In hypothalamus, FEN-pretreated rats displayed significantly diminished 5 -HT in the ventromedial region ( $46 \%$ decrease) $\left(F_{(1,14)}=18.2\right.$; $p<0.001)$ but not in the lateral region $(6 \%$ decrease $)\left(F_{(1,14)}=\right.$ $0.33 ; p<0.58$ ). In general, the 5-HIAA data in Figure 8 parallel the findings noted for 5 -HT.

\section{DISCUSSION}

In the current study, FEN-induced depletion of forebrain 5-HT was accompanied by a reduction in neuroendocrine and behav- 

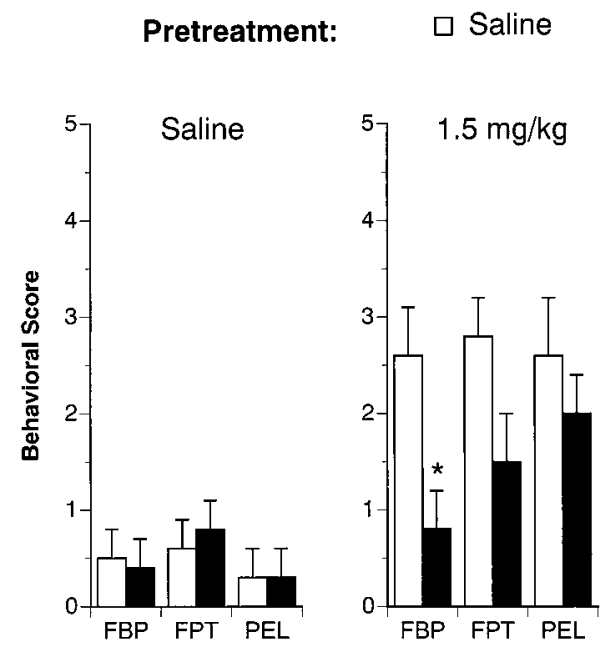

- Fenfluramine

Figure 6. FEN-induced behavioral responses evaluated 2 weeks after the $4 \mathrm{~d}$ saline or FEN-dosing regimen. The data depicted here are obtained from the same subjects described in Figure 5. Refer to the legend of Figure 5 for further details. $n=8$ rats per group. ${ }^{*} p<0.05$ with respect to corresponding saline pretreatment group.

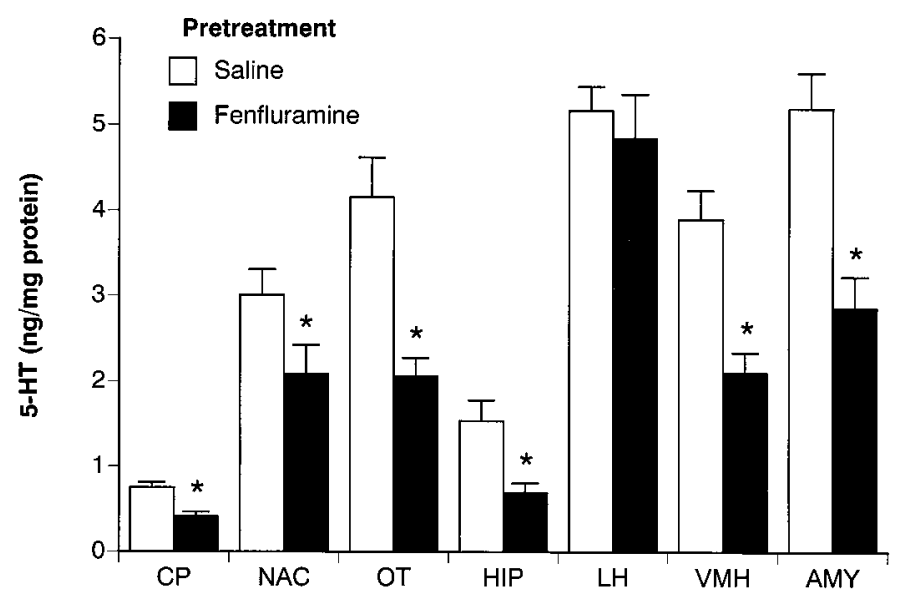

Figure 7. Postmortem tissue levels of 5-HT in microdissected brain regions from rats challenged with acute saline. Rats had previously received repeated saline or FEN for $4 \mathrm{~d}$ and were decapitated 2 weeks later after the final challenge test session. Micropunches of tissue were assayed for 5-HT by HPLC-EC techniques (see Materials and Methods). Regions examined were caudate putamen $(C P)$, nucleus accumbens $(N A C)$, olfactory tubercle $(O T)$, hippocampus CA3 (HIP), lateral hypothalamus $(L H)$, ventromedial hypothalamus $(V M H)$, and basolateral amygdala $(A M Y)$. Data are mean \pm SEM expressed as nanograms per milligrams of protein for $n=8$ rats per group. ${ }^{*} p<0.05$ compared with saline pretreatment group.

ioral responsiveness to subsequent FEN challenge. The simplest explanation for these results is that diminished sensitivity to FEN reflects presynaptic 5-HT dysfunction in rats previously exposed to the drug. Our data are reminiscent of the findings of Kleven et al. (1988) who demonstrated tolerance to the anorectic effect of FEN in rats pretreated with 5-HT-depleting doses of FEN. It is noteworthy that no overt hormonal or behavioral abnormalities were observed under basal conditions in the FEN-pretreated rats from our study. Only after perturbation of the 5-HT system via acute FEN injection were the functional changes unmasked.

An accurate interpretation of our data relies on the assumption that the FEN-induced responses we chose to examine involve central 5-HT mechanisms. The neural substrates responsible for

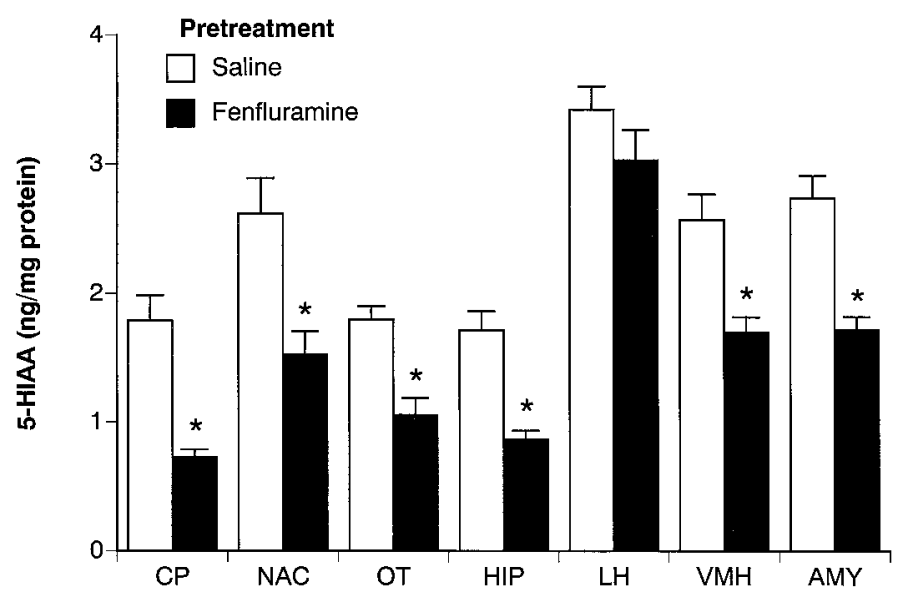

Figure 8. Postmortem tissue levels of 5-HIAA in microdissected brain regions from rats challenged with acute saline. Rats had previously received repeated saline or FEN for $4 \mathrm{~d}$ and were decapitated 2 weeks later after the final challenge test session. Micropunches of tissue were assayed for 5-HIAA by HPLC-EC techniques (see Materials and Methods). Data are mean \pm SEM expressed as nanograms per milligram of protein for $n=8$ rats per group. ${ }^{*} p<0.05$ compared with saline pretreatment group.

5-HT-mediated neuroendocrine and behavioral effects are presumably localized in the hypothalamus and brainstem, respectively (Levy et al., 1994a; Wilkinson and Dourish, 1991). Although the FEN-evoked prolactin response is known to involve central 5-HT systems, the role of 5-HT in the accompanying corticosterone response is controversial (McElroy et al., 1984; Levy et al., 1994b; Van de Kar et al., 1985). We used the criterion of fluoxetine reversibility to evaluate the 5-HT specificity of hormonal effects of FEN; fluoxetine antagonizes in vivo actions of FEN by blocking 5-HT reuptake sites and thereby preventing 5-HT-release (Levy et al., 1994a). Our data showed that fluoxetine significantly attenuates FEN-induced corticosterone and prolactin secretion. However, fluoxetine did not totally abolish the hormonal effects of FEN, and there are several possibilities that might explain this finding. For example, the dose of fluoxetine that we used (i.e., $5 \mathrm{mg} / \mathrm{kg}$, i.p.) may not be sufficient to completely block all 5-HT transporter sites (Fuller et al., 1977; Levy et al., 1994b). Alternatively, FEN may possess direct postsynaptic receptor actions that are not antagonized by fluoxetine pretreatment (Oluyomi et al., 1994; Raiteri et al., 1995). Irrespective of the such arguments, our results indicate that FEN-induced corticosterone and prolactin responses are at least partially mediated by 5-HT mechanisms. Trulson and Jacobs (1976) reported that the 5-HT syndrome elicited by FEN is prevented after depletion of 5-HT with the synthesis inhibitor parachlorophenylalanine. Thus, the available evidence supports the notion that FEN-induced endpoints assessed in the present study represent valid indices of central 5-HT function.

Prior exposure to repeated FEN administration markedly reduced subsequent FEN-evoked corticosterone secretion, and this effect was observed at both challenge doses for at least 2 weeks. Our data agree with those of Appel et al. (1991) who found corticosterone responses to FEN are blunted on the final day of a 4 d FEN-dosing regimen. Similarly, Pinto et al. (1996) demonstrated that D-FEN-stimulated ACTH secretion is impaired 2 weeks after exposure to repeated doses of D-FEN $>2.0 \mathrm{mg} / \mathrm{kg}$. In their study, deficits in ACTH secretion were positively correlated with the degree of central 5-HT depletion. The collective data 
indicate that repeated FEN administration causes functional impairments in 5-HT neurons modulating the hypothalamicpituitary-adrenal (HPA) axis. A related finding from our work was that stress-induced corticosterone secretion appeared compromised in rats with 5-HT depletion. Our challenge test procedure represents a minor stressor that causes a reliable, albeit modest, elevation of plasma corticosterone (Baumann et al., 1995). The typical transient increase in corticosterone produced by saline injection was completely absent in rats pretreated with FEN. Whether the sensitivity to other more potent stressors is altered after FEN pretreatment is unknown, but our findings suggest 5-HT plays a role in the stress-induced activation of the HPA axis.

Prior exposure to FEN also decreased the FEN-induced secretion of prolactin, but this effect was qualitatively different from the corticosterone results. More precisely, prolactin responses to FEN were blunted only at the high challenge dose in rats exhibiting 5-HT depletion. Our results are at odds with those of Pinto et al. (1996) who found repeated D-FEN pretreatment did not alter subsequent prolactin responses to D-FEN. It is feasible that methodological differences between our work and theirs can account for this discrepancy. In any event, the data from both studies imply that 5-HT control of prolactin secretion remains relatively stable despite reductions in brain 5-HT. On the other hand, FEN-induced 5-HT depletion may disrupt physiologically relevant prolactin secretion when large surges of the hormone are common, such as during lactation. Rowland et al. (1978) reported that pretreatment with parachloroamphetamine, which depletes brain 5-HT similar to FEN, reduces the suckling-induced prolactin response in lactating rats.

Distinct components of the 5-HT behavioral syndrome, namely flat body posture and forepaw treading, are mediated predominately by 5-HT receptors (Tricklebank et al., 1985; Wilkinson and Dourish, 1991). We found that FEN-induced flat body posture was nearly eliminated in FEN-pretreated rats, whereas forepaw treading was less affected. These results are comparable to the findings of Trulson et al. (1976) who found a marked reduction in the ability of FEN to elicit the 5-HT behavioral syndrome after depletion of 5-HT with the neurotoxin, 5,7-dihydroxytryptamine (5,7-DHT). Likewise, Kleven et al. (1988) reported tolerance to the anorectic effect of FEN in FEN-pretreated rats, and this effect lasted up to 8 weeks. In contrast, FEN-induced penile erections were not altered by previous FEN exposure. One possible explanation for this finding is that FEN evokes penile erections by direct 5-HT receptor activation. As eluded to previously, accumulating evidence suggests that some effects of FEN are mediated independent of presynaptic 5-HT actions (Oluyomi et al., 1994; Raiteri et al., 1995).

The present neurochemical data showed that FEN-pretreated rats display a significant loss of 5-HT and 5-HIAA in the ventromedial hypothalamus ( $\mathrm{VMH}$ ), whereas the lateral hypothalamus (LH) is unaffected. The degree of 5-HT depletion in the VMH was similar to other vulnerable areas such as the caudate putamen and amygdala. It is noteworthy that the microdissected brain region we refer to as the $\mathrm{VMH}$ actually included the medial and lateral subdivisions of the ventromedial hypothalamic nucleus, as well as portions of the arcuate nucleus (Palkovits and Brownstein, 1988); these nuclei are known to contain high densities of 5-HT nerve terminals (Steinbusch, 1981; Molliver, 1987). The neighboring region we designate as the LH contained predominately axon tracts of the median forebrain bundle. Based on our results from the hypothalamus, it appears that 5-HT nerve terminals are more susceptible to FEN-induced 5-HT depletion when compared with fibers of passage. Some studies have found the hypothalamus to be resistant to the 5-HT-depleting effects of FEN (Kleven et al., 1988; Zaczek et al., 1990). This apparent incongruity can be resolved on the basis of the dissection method used to excise the hypothalamus: a dissection which includes the $\mathrm{LH}$ would tend to mask the severity of 5-HT depletion occurring in the VMH. The present findings show the utility of the micropunch technique for sampling subdivisions of heterogenous brain areas like the hypothalamus.

Similar to the findings of others (for review, see Ricaurte et al., 1994), we found no overt changes in basal neuroendocrine or behavioral parameters in FEN-pretreated rats. Stated more simply, it was impossible to distinguish which rats exhibited 5-HT depletion without testing them in a very specific manner. This observation is surprising based on the alleged role of 5-HT in the integration of diverse motor and vegetative functions (Jacobs and Fornal, 1995). One feasible explanation for this apparent paradox is that neuroadaptive mechanisms are recruited to keep synaptic 5-HT levels constant despite FEN-induced depletion of brain 5-HT. Recent in vivo microdialysis findings from rats support this proposal. Series et al. (1994) depleted brain 5-HT using various amphetamine derivatives, including FEN, and then monitored dialysate 5-HT in the cortex 2 weeks later. These investigators found that 5-HT depletion did not affect basal dialysate levels of 5-HT but severely impaired the ability of FEN to elicit 5-HT release. Virtually identical results were reported by Kirby et al. (1995) who lesioned brain 5-HT neurons with 5,7-DHT. Thus, it appears that compensatory mechanisms maintain optimal levels of synaptic 5-HT when tissue levels of 5-HT are depleted. Only on acute perturbation of the 5-HT system by pharmacological challenge can the functional deficits in 5-HT transmission be revealed.

The potential clinical relevance of our data deserves comment. Recently, racemic FEN and D-FEN have been withdrawn from clinical use because of the occurrence of cardiac valve abnormalities in some patients (Connolly et al., 1997). Despite the fact that FEN is no longer prescribed, lingering doubts about long-term neurotoxicity might still be a concern for people who have taken the drug. With respect to this issue, several points are worth mentioning. First, whether FEN-induced 5-HT depletion in animals actually reflects true neurotoxicity is a debatable issue, and the mechanisms underlying such 5-HT loss are not known (Baumann and Rothman, 1998; McCann et al., 1997). Second, because of profound species differences in vulnerability to FEN-induced 5-HT depletion (McCann et al., 1994; Fracasso et al., 1995), direct extrapolation of animal data to humans is unwarranted. Finally, it should be noted that the dose of FEN used in the present study to decrease brain 5-HT levels (i.e., $20 \mathrm{mg} / \mathrm{kg}$, s.c.) is much greater than the typical doses used to suppress feeding (i.e., 1-3 mg/kg, i.p.) in rats (Cox and Maickle, 1972; Kleven et al., 1988). Thus, the present findings per se do not provide support for, or against, the occurrence of 5-HT neurotoxicity in humans. Our results do suggest that the FEN challenge paradigm is a plausible method for identifying potential 5-HT dysfunction in patients who have taken FEN as an appetite suppressant. Indeed, the FEN challenge test has been widely used in psychiatry as a safe and reliable way to assess 5-HT neurotransmission (Siever et at., 1991).

In summary, the data presented herein confirm that repeated FEN administration decreases forebrain 5-HT in rats, and the degree of 5-HT depletion in the VMH was similar to other 
susceptible brain regions. More importantly, FEN-induced 5-HT loss was associated with reduced neuroendocrine and behavioral responsiveness to acute FEN challenge. These effects were sustained, lasting for at least 2 weeks. In conjunction with in vivo microdialysis studies, our results indicate that blunted sensitivity to FEN reflects deficits in presynaptic 5-HT function in the rats with central 5-HT depletion. As discussed above, the clinical relevance of our data are not known. However, the present findings clearly illustrate the usefulness of the FEN challenge test for uncovering changes in 5-HT neurotransmission that might otherwise go undetected (Baumann et al., 1995). Thus, although FEN is no longer available as an appetite suppressant, this drug should remain an important tool for examining the involvement of 5-HT neurons in diverse physiological and behavioral processes.

\section{REFERENCES}

Appel NM, Contrera JF, De Souza EB (1989) Fenfluramine selectively and differentially decreases the density of serotonergic nerve terminals in rat brain: evidence from immunocytochemical studies. J Pharmacol Exp Ther 249:928-943.

Appel NM, Mitchell WM, Contrera JF, De Souza EB (1990) Effects of high-dose fenfluramine treatment on monoamine uptake sites in rat brain: assessment using quantitative autoradiography. Synapse 6:33-44.

Appel NM, Owens MJ, Culp S, Zaczek R, Contrera JF, Bissette G, Nemeroff CB, De Souza EB (1991) Role for brain corticotropinreleasing factor in the weight-reducing effects of chronic fenfluramine treatment in rats. Endocrinology 128:3237-3246.

Auerbach SB, Minzenberg MJ, Wilkinson LO (1989) Extracellular serotonin and 5-hydroxyindoleacetic acid in hypothalamus of the unanesthetized rat measured by in vivo dialysis coupled to high-performance liquid chromatography with electrochemical detection. Brain Res 499:281-290.

Baumann MH, Rothman RB (1998) Combined phentermine/fenfluramine administration and central serotonin neurons. Synapse 28:339-342.

Baumann MH, Raley TJ, Partilla JS, Rothman RB (1993) Biosynthesis of dopamine and serotonin in rat brain after repeated cocaine injections: a microdissection mapping study. Synapse 14:40-50.

Baumann MH, Becketts KM, Rothman RB (1995) Evidence for alterations in presynaptic serotonergic function during withdrawal from chronic cocaine. Eur J Pharmacol 282:87-93.

Berger UV, Gu XF, Azmitia EC (1992) The substituted amphetamines 3,4-methylenedioxymethamphetamine, methamphetamine, $p$-chloroamphetamine and fenfluramine induce 5-hydroxytryptamine release via a common mechanism blocked by fluoxetine and cocaine. Eur J Pharmacol 215:153-160.

Bradford MM (1976) A rapid and sensitive method for quantitation of microgram quantities of protein utilizing the principles of dye binding. Anal Biochem 72:248-254.

Carboni E, Di Chiara G (1989) Serotonin release estimated by transcortical dialysis in freely-moving rats. Neuroscience 32:637-645.

Clineschmidt BV, Totaro JA, McGuffin JC, Pflueger AB (1976) Fenfluramine: long-term reduction in brain serotonin (5-hydroxytryptamine). Eur J Pharmacol 35:211-214.

Connolly HM, Crary JL, McGoon MD, Hensrud DD, Edwards BS, Schaff HV (1997) Valvular heart disease associated with fenfluraminephentermine. N Engl J Med 337:581-588.

Cox RH, Maickle RP (1972) Comparison of anorexigenic and behavioral potency of phenylethylamines. J Pharmacol Exp Ther 181:1-9.

Fracasso C, Guiso G, Confalonieri S, Bergami A, Garattini S, Caccia S (1995) Depletion and time-course of recovery of brain serotonin after repeated subcutaneous dexfenfluramine in the mouse: a comparison with the rat. Neuropharmacology 34:1653-1659.

Fuller RW, Snoddy HD, Perry K, Bymaster FP, Wong DT (1977) Importance of duration of drug action in the antagonism of $p$-chloroamphetamine depletion of brain serotonin: comparison of fluoxetine and chlorimipramine. Biochem Pharmacol 27:193-198.

Fuller RW, Snoddy HD, Robertson DW (1988) Mechanism of effects of D-fenfluramine on brain serotonin metabolism in rats: uptake inhibition versus release. Pharmacol Biochem Behav 30:15-721.
Fuxe K, Hamberger B, Farnebo L-O, Ogren S-O (1975) On the in vivo and in vitro actions of fenfluramine and its derivatives on central monoamine neurons, especially 5-hydroxytryptamine neurons, and their relation to the anorectic activity of fenfluramine. Postgrad Med J [Suppl 1] 51:35-45.

Garattini S, Buczko W, Jori A, Samanin R (1975) The mechanism of action of fenfluramine. Postgrad Med J [Suppl 1] 51:27-35.

Harvey JA, McMaster SE (1975) Fenfluramine: evidence for a neurotoxic action on midbrain and long-term depletion of serotonin. Psychopharmacol Commun 1:217-228.

Jacobs BL, Fornal CA (1995) Serotonin and behavior. In: Psychopharmacology: the fourth generation of progress. (Bloom FE, Kupfer DJ, eds) pp 461-469. New York: Raven.

Kirby LG, Kreiss DS, Singh A, Lucki I (1995) Effects of destruction of serotonin neurons on basal and fenfluramine-induced striatal serotonin release. Synapse 20:99-105.

Kleven MS, Schuster CR, Seiden LS (1988) Effect of depletion of brain serotonin by repeated fenfluramine on neurochemical and anorectic effects of acute fenfluramine. J Pharmacol Exp Ther 246:822-828.

Levy AD, Baumann MH, Van de Kar LD (1994a) Monoaminergic regulation of neuroendocrine function and its modification by cocaine. Front Neuroendocrinology 15:85-156.

Levy AD, Li Q, Van de Kar LD (1994b) Repeated cocaine exposure inhibits the adrenocorticotropic hormone response to the serotonin releaser D-fenfluramine and the $5-\mathrm{HT}_{1 \mathrm{~A}}$ agonist, 8-OH-DPAT. Neuropharmacology 33:335-324.

McCann U, Hatzidimitriou G, Ridenour A, Fischer C, Yuan J, Katz J, Ricaurte G (1994) Dexfenfluramine and serotonin neurotoxicity: further preclinical evidence that clinical caution is indicated. J Pharmacol Exp Ther 269:792-798.

McCann UD, Seiden LS, Rubin LJ, Ricaurte GA (1997) Brain serotonin neurotoxicity and primary pulmonary hypertension from fenfluramine and dexfenfluramine. J Am Med Assoc 278:666-672.

McElroy JF, Miller JM, Meyer JS (1984) Fenfluramine, p-chloroamphetamine and $p$-fluoroamphetamine stimulation of pituitaryadrenocortical activity in rat: evidence for differences in site and mechanism of action. J Pharmacol Exp Ther 228:593-600.

McTavish D, Heel RC (1992) Dexfenfluramine: a review of its pharmacological properties and therapeutic potential in obesity. Drugs 43:713-733.

Molliver ME (1987) Serotonergic neuronal systems: what their anatomic organization tells us about function. J Clin Psychopharmacol 7:3S-23S.

Molliver DC, Molliver ME (1990) Anatomic evidence for a neurotoxic effect of $( \pm)$ fenfluramine upon serotonergic projections in the rat. Brain Res 511:165-168.

Oluyomi AO, Gibson EL, Barnfield AM, Curzon G (1994) D-Fenfluramine and D-norfenfluramine hypophagias do not require increased hypothalamic 5-hydroxytryptamine release. Eur J Pharmacol 264:111-115.

Palkovits M, Brownstein MJ (1988) Maps and guide to microdissection of the rat brain. New York: Elsevier.

Pinto W, Garcia F, Li Q, Vincentic A, Van de Kar LD, Wolf WA, Battaglia G (1996) Dexfenfluramine produces dose-dependent biochemical and functional impairment of brain serotonin systems. Soc Neurosci Abstr 26:125.

Raiteri M, Bonnano G, Vallebuona F (1995) In vitro and in vivo effects of D-fenfluramine: no apparent relation between 5-hydroxytryptamine release and hypophagia. J Pharmacol Exp Ther 273:643-649.

Ricaurte GA, Molliver ME, Martello MB, Katz JL, Wison MA, Martello AL (1991) Dexfenfluramine neurotoxicity in brains from non-human primates. Lancet 338:1487-1488.

Ricaurte GA, Sabol KE, Seiden LS (1994) Functional consequences of neurotoxic amphetamine exposure. In: Amphetamine and its analogs: psychopharmacology, toxicology, and abuse (Cho AK, Segal DS, eds), pp 297-313. San Diego: Academic.

Rowland NE, Carlton J (1986) Neurobiology of the anorectic drug fenfluramine. Prog Neurobiol 27:13-62.

Rowland DC, Steele M, Moltz H (1978) Serotonergic mediation of the suckling-induced release of prolactin in the lactating rat. Neuroendocrinology 26:8-14.

Sabol KE, Richards JB, Seiden LS (1992) Fluoxetine attenuates the D,L-fenfluramine-induced increase in extracellular serotonin as measured by in vivo microdialysis. Brain Res 585:421-424.

Sanders-Bush E, Bushing JA, Sulser F (1975) Long-term effects of 
p-chloroamphetamine and related drugs on the central serotonergic mechanisms. J Pharmacol Exp Ther 192:33-41.

Schwartz D, Hernandez L, Hoebel BG (1989) Fenfluramine administered systemically or locally increases extracellular serotonin in the lateral hypothalamus as measured by microdialysis. Brain Res 482:261-270.

Series HG, Cowen PJ, Sharp T (1994) P-chloroamphetamine (PCA), 3,4-methylenedioxymethamphetamine (MDMA) and D-fenfluramine pretreatment attenuates D-fenfluramine-evoked release of 5-HT in vivo. Psychopharmacology 116:508-514.

Siever LJ, Kahn RS, Lawlor BA, Trestman RD, Lawrence TL, Coccaro EF (1991) Critical issues in defining the role of serotonin in psychiatric disorders. Pharmacol Rev 43:509-525.

Silverstone T (1992) Appetite suppressants: a review. Drugs 43:820-836.

Steinbusch HWM (1981) Distribution of serotonin-immunoreactivity in the central nervous system of the rat: cell bodies and terminals. Neuroscience 6:557-618.

Tricklebank MD, Forler C, Fozard JR (1985) The involvement of subtypes of the $5-\mathrm{HT}_{1}$ receptors and of catecholaminergic systems in the behavioural responses to 8-hydroxy-2-(di-n-propylamino)tetralin in the rat. Eur J Pharmacol 106:271-282.

Trulson ME, Jacobs BL (1976) Behavioral evidence for the rapid release of CNS serotonin by PCA and fenfluramine. Eur $\mathrm{J}$ Pharmacol 36:149-154.

Trulson ME, Eubanks EE, Jacobs BL (1976) Behavioral evidence for supersensitivity following destruction of central serotonergic nerve terminals by 5,7-dihydroxytryptamine. J Pharmacol Exp Ther 198:23-32.

Van de Kar LD (1991) Neuroendocrine pharmacology of serotonergic (5-HT) neurons. Annu Rev Pharmacol Toxicol 31:289-320.

Van de Kar LD, Urban JH, Richardson KD, Bethea CL (1985) Pharmacological studies on the serotonergic and nonserotonin-mediated stimulation of prolactin and corticosterone secretion by fenfluramine. Neuroendocrinology 41:283-288.

Wilkinson LO, Dourish CT (1991) Serotonin and animal behavior. In: Serotonin receptor subtypes: basic and clinical aspects. (Peroutka SJ, ed) pp 147-210. New York: Wiley-Liss.

Yatham LN, Steiner M (1993) Neuroendocrine probes of serotonergic function: a critical review. Life Sci 53:447-463.

Zaczek R, Battaglia G, Culp S, Appel NM, Contrera JF, De Souza EB (1990) Effects of repeated fenfluramine administration on indices of monoamine function in rat brain: pharmacokinetic, dose response, regional specificity and time course data. J Pharmacol Exp Ther 253: $104-112$. 